\title{
学分制下地方本科院校学生自主学习现状及提升路径研究
}

\author{
刘洁晶 康秀平 李永霞 张新民王洪安 \\ 衡水学院
}

DOI:10.32629/er.v3i4.2623

[ 摘 要] 在深入分析学分制对地方本科院校带来的机遇和挑战的基础上,通过问卷等方法调研地方高校学生自主学习存在学习动力不足、自主 学习欠缺规划、自主学习方式方法较为传统、自主学习尚需进一步监督机制等问题,并基于学分制改革探索形成加强宣传提高自主学习动力, 注重引导制定明确学业规划,强化创新重视学习指导,完善制度提升自学监督保障等,提高大学生自主学习的对策。

[关键词] 学分制; 地方本科院校; 学生自主学习; 现状; 对策

近年来, 随着高等教育的改革和发展, 特别是教育部等部委《关于引导 部分地方普通本科高校向应用型转变的指导意见》(教发 [2015]7号)、《国 家中长期教育改革和发展规划纲要 (2010-2020年)》等明确了地方本科院 校教学管理的改革方向。新时代全国教育大会及《教育部关于加快建设高 水平本科教育全面提高人才培养能力的意见》( “新时代高教 40 条”) 等系 列文件的发布, 提出 “完善学分制, 推动健全学分制收费管理制度, 扩大学 生学习自主权、选择权” ${ }^{[1]}$, 以实现学生自主能力的提升, 提高大学生自主 学习动力, 还原学生学习主体的地位等。大学生自主学习能力作为当代大 学生核心素养之一, 得到众多高等教育专家和学者的广泛关注。如何将大 学生自主学习能力的培养与新时代地方高校振兴本科教育实现学分制管 理相融合, 以衡水学院为例, 开展基于学分制背景下地方本科院校学生自 主学习现状调研, 探索提升其发展的路径体系。

\section{1 学分制改革的机遇与挑战}

1. 1 学分制为学生个性发展创设良好的条件

学分制源于美国哈佛大学19世纪采取的以学分作为计算学生学习单 位, 以取得最低必要学分作为毕业标准的一种教学管理模式 ${ }^{[2]}$ 。与学年制 教学管理模式相比, 学分制教学管理模式由于其是以课程选修为基础, 以 课程所对应的学分作为学生毕业标准, 极大的激发了学生学习的主动性, 为学生个性化的成长与发展创设了良好的课程资源平台, 变传统的固定专 业、固定课程、固定课表、固定师资的 “计划” 教学, 为学生可凭兴趣爱 好多样化选择的专业、课组、课表、教师的 “市场” 教学, 还原了学生学 习的主体地位, 同时也为学生加快学习进度提前毕业, 或放慢学习进度休 退转复等弹性学制的实施提供了可能, 充分体现学生学习的个性化, 为复 合式、创新型、应用型人才培养创奠定了基础。

1.2 学分制对教学管理提出新要求

学分制教学管理在激励学生个性化发展的同时, 对教学管理提出了新 挑战。传统的固定专业的招生、固定专业的人才培养方案、单一化的人才 培养模式、学生被动服从的固定教师、教室、时间的课表安排等教学管理 模式, 难以满足灵活、多样而广阔的学分制教学运行要求及学生个性化发 展的需要。学分制运行实施, 倒逼转变教学管理理念, 立足以学生发展为中 心对教学管理改革创新, 放权学生、教师及各教学单位, 盘活全校教室、实 验室、实践基地等教学资源和设施条件, 充分调动全校教师资源, 引导各教 学单位、专业明确人才培养标准, 优化学分制人才培养及学分制收费相关 制度、流程, 完善选课机制, 主动服务超前及休退转复个性化学生发展。学 分制的实施对高校教室、实验室、实践基地等教学资源, 教师资源、教学 管理制度流程, 教学建设、教学运行等提出新要求。

\section{2 地方院校学生自主学习现状}

通过以衡水学院为例, 采用分层随机取样的方式, 1200名2016-2019级
在校本科生开展基于学分制大学生自主学习现状及提升路径的问卷及访 谈调查, 通过对衡水学院在校大学生自主学习整体情况、自主学习的学习 态度、自主学习的学习目的、自主学习的学习频次、自主学习自控能力、 学习计划的制定与完成等具体情况调查, 结果发现绝大部分同学能进行自 主学习, 但也存在以下问题:

2.1自主学习动力不足

调研发现, 地方本科院校绝大部分学生了解自主学习的重要性, 但其开 展自主学习受 “自觉、喜欢等” 内在目标影响的仅占 $37 \%, 63 \%$ 的学生受 “教 师要求、就业或考研需要、家长要求或同学激励等” 外在目标影响。由此 可见地方本科院校大部分学生自主学习动力不足。究其原因, 首先, 主要在 于在校大学生自身对自主学习认识程度有限, 尚未完全通过学习态度观念 的转变, 实现观念引导行动的效果; 其次, 在于学生素质能力有限, 作为二本 院校学生, 虽然在综合素质方面比专科层次、三本院校学生略好, 但在自律 性、自省、认知深度等方面, 仍与一本院校学生有一定差距。

2.2 自主学习欠缺规划

通过对学生自主学习开展的频次、计划、计划落实及自评效果等方面 的调研, 发现大部分学生自主学习欠缺规划。主要表现在就自主学习开展 的频次而言, 地方本科院校78\%的大一学生、68\%的大四学生自主学习频次 较高, 平均每周五次; 就自主学习计划制定情况而言, 制定计划最多的是大 一学生 $83 \%$, 最少的是大四学生 $12 \%$; 就自主学习计划落实及自评效果而言, 大一学生自主学习计划落实及自评效果较高占 $69 \%$, 计划落实及自评效果 较低的是大三为 $8 \%$ 。分析原因, 一方面是学生自主学习的规划意识不足, 另一方面, 学生缺乏大学全学程的自主学习规划、指导与帮扶。

2. 3自主学习方式方法较为传统

调研发现, 地方本科院校在校大学生自主学习的途径、方式方法中占 比较多的分别是个人看书 $(52 \%)$ 、做作业练习 (41\%)、预习 (32\%)、复习 (21\%)。可见学生绝大部分自主学习方式方法以传统的学习方式方法为主, 缺乏多样化的互联网、大数据、云平台、新信息技术运用, 多人协作等的 自主学习方式。分析其原因, 一方面是学生习惯于中小学阶段积累的传统 学习方式, 欠缺关于团队合作学习、新信息技术学习等多样的自主学习方 法的体验; 其次, 高校教师往往在课堂上注重知识、技能的教学, 习惯于传 统的教学方式, 缺乏给予学生自主学习的引导及其习惯的养成锻炼。

2.4自主学习尚需进一步监督机制

通过问卷及访谈调研, 发现 $85 \%$ 的学生自主学习未坚持的原因在于缺 乏自我及外部的监督和提醒, 可见, 地方本科院校在校生自主学习尚需完 善监督机制。主要表现在, 学生绝大部分缺乏系统的学习计划的制定, 缺少 分阶段学习计划的落实实施, 欠缺分阶段自主学习的反思与改进等。其原 因主要包括: 首先, 学生自主自觉开展学习的意识较欠缺, 其次, 学生多数 
是按照教师要求、所学专业要求及学校相关要求开展学习, 其能根据自己 兴趣、爱好选择的机会较少; 第三, 学校、教师也缺少对学生自主学习监 督、评价与督促的制度、机制。

\section{3 学分制背景下提升学生自主学习对策研究}

衡水学院2012年开始探索辅修专业, 积极进行大类招生等系列学分制 教学改革, 2016年被确立为河北省第二批学分制收费改革试点, 探索形成 “学生中心, 招生就业联动, 校、院、专业、教师、学生及用人单位六位一 体” 的基于学分制改革的大学生自主学习提升体系, 主要通过以下措施促 进该校学生自主学习的有效开展。

\section{1加强宣传, 提高自主学习动力}

学校是学生进行自主学习的主要场所, 学生是自主学习的主人。要从 根本上提高学生学习的主动性、积极性及自主学习能力, 以提升学分制教 学改革效果及学生发展的质量, 首要是提高学生自身自主学习的动力。主 要通过学校、各教学单位、专业、班级等网站、自媒体等, 加强学生自主 学习的宣传, 营造主动开展自主学习的氛围; 以开展入学导航、学程学业 引导、毕业教育等专题讲座, 激发学生自主学习的外动力; 以自主学习宣 传月、实践周、第二课堂、创新创业竞赛、劳动教育实践、社团及学生系 列竞赛活动, 为学生创设个性发展的活动平台, 激励学生在做中体验自主 学习的乐趣, 进而激发其自主学习的内动力。

\section{2注重引导, 制定明确学业规划}

在激发学生自主学习动力的基础上, 明确学校、教学单位、教师对学 生自主学习的引导。通过《大学生职业生涯规划》、《大学生学业规划》等 系列课程、讲座的开设与学习, 引导学生明确自身发展远期、中期、近期 目标, 并根据不同阶段的目标, 分阶段制定大学四年、学年、学期、月、周、 日等系列学业规划。通过分年度 “我的学业规划” 评比、演讲、展示等系 列活动, 激发学生们坚持制定并实施学业规划, 积极开展自主学习, 不断在 自主学习过程中修正学业规划, 养成 “计划一实施一检查反思一改进” 的 循环提升, 终身学习的习惯。

\section{3 强化创新, 重视学习指导}

根据学分制教学管理的改革要求及学生自主学习的需要, 我校创新学 生学业指导机制, 形成以满足学生个性化学习发展为目标, 学校、教学单 位、专业、教研室、课程组、任课教师、学业导师、辅导员、社团负责人 等多元参与, 通过课程思政、心理育人、管理育人、服务育人、实践育人 等, 将对大学生自主学习的学习方法等系列指导贯穿于学分制人才培养的 全过程, 以切实提高大学生自主学习能力 ${ }^{[3]}$ 。

3. 4 完善制度, 提升自学监督保障

教学管理层面, 需要不断完善基于学分制管理的自主学习服务监管机 制。首先, 健全学分制背景下, 自主学习相关文件制度, 完善学分制教学管 理、大类招生、学习管理、人才培养方案、学务指导等多项文件制度; 其 次, 制定契合学分制教学管理的适于学生自主学习的人才培养方案, 引导 理论类的公共课、专业课, 以学生发展为中心, 以成果为导向, 适当设置自 主学时, 且实施弹性学制3-6年, 设置辅修、转专业等机制, 以满足当兵、入 伍、提前毕业、休学复学及学生主辅修多元个性发展需求; 第三, 加强基 于学分制的大学生自主学习能力培养课程教学改革, 通过课程思政、专业 思政等多形式, 系统统筹大学生自主学习能力提升系列课程, 科学设置相 关课程的自主学习学时学分, 以联合课程组、校企教研等, 共同研讨大学生 自主学习指导大纲等; 第四, 强化学生学情及自主学习需求调研, 根据调研
的需求, 针对性的组建校、二级学院及基层教学组织多级联动的学生自主 学习帮扶组, 提高学分制运行过程中大学生自主学习指导等的针对性; 第 五, 切实提供学分制背景下大学生自主学习能力提升的配套保障, 通过筹 建衡水学院滨湖新校区扩大教学空间, 积极开展教师三年工程, 提升教师 素质以满足新时代本科教育改革需求, 利用互联网 + 、大数据技术升级学校 教学管理系统, 设置线上线下课程资源库, 升级校园网络配置, 加强校园网 络安全管理, 进行智慧校园、智慧教室建设等多机制, 为学分制运行中学生 自主学习提供切实的保障; 第六, 加强对大学生自主学习的监督检查管理 等, 通过教务系统学分核对、课程修读与选课查询、分学段在校任课教师、 辅导员、实践用人单位对学生的评价意见, 开展专业认证与评估、生源调 研、学情调研、第三方毕业生追逐调研等, 为学生自主学习的开展提供阶 段性反馈机制, 并通过教学管理、学生管理、课程管理、实践管理等多维 度激励学生主动开展自主学习, 及时制定自主学习规划, 并实践反思与改 进。从自主学习教学管理制度的制定, 到深入学生自主学习现状调研, 针对 性的从网络教学技术、电脑自主学习途径与场所、多样化交互互动的自主 室等进行改善, 并强化多元主体的监督检查, 以期满足学生自主学习的发 展需求, 为其提供自主学习的教学管理服务, 提高大学生自主学习能力, 为 我校及其他地方本科院校人才培养模式改革提供参照。

\section{[参考文献]}

[1]教育部.教育部关于加快建设高水平本科教育全面提高人才培养能力的意 见[EB/OL].http:/hww.moe.gov.cn/srcsite/A08/s7056/201810/t20181017_351887htm1.

[2]马云华,刘轶,胡晓艳.学分制教学管理模式下大学生自主学习能力 的培养[J].赤峰学院学报,2012(8):240-241.

[3]马赛,郝智秀.学分制在哈佛大学创立和发展的历史轨迹——兼论 美国学分制产生和发展的社会背景[J].高教探索,2009(01):70-75.

\section{作者简介：}

刘洁晶(1981--), 男, 汉族, 河北景县人, 硕士研究生, 副教授, 研究方 向: 高等教育管理、数据处理,从事工作高教管理。

康秀平(1981--), 女, 汉族, 河北故城人, 硕士研究生, 副教授, 研究方 向：高教管理、新闻传播,从事高教管理。

李永霞(1984--), 女, 汉族, 河北沧州人, 硕士研究生, 副教授, 研究方 向：高教管理,从事高教管理。

张新民(1983--), 男, 汉族, 河北臬强人, 硕士研究生, 讲师, 研究方 向：高教管理,从事高教管理。

王洪安(1973--), 男, 汉族, 河北冀州人, 硕士研究生, 高级讲师, 研究 方向：高教管理,从事高教管理。

\section{基金项目:}

河北省高等教育教学改革研究项目 “学分制下地方本科院校学生 自主学习现状及其提升路径研究”(2017GJJG283)。

河北省高等教育教学改革研究项目 “基于数据分析的地方院校专 业评估预警机制研究” (2018GJJG569)。

河北省高等教育教学改革研究项目 “新时代背景下项目驱动模式 的专业课程改革研究” (2018GJJG568)。

河北省高等教育教学改革研究项目 “新时代地方院校振兴本科教 育教学改革体系构建研究” (2019GJJG518)。

河北省高等教育教学改革研究项目 “新工科背景下地方高校计算 机专业实践育人体系探索与实践” (2019GJJG522)。 